\title{
Demographic Changes as Triggers for the Loss of Skills during the Lower Palaeolithic Levant
}

\author{
Nira Alperson-Afil* \\ Martin (Szusz) Department of Land of Israel Studies and Archaeology, Institute of Archaeology, Bar-Ilan University, Israel
}

\section{Introduction}

Locke's publication "An Essay Concerning Human Understanding" [1] may mark the first modern elaboration of the definition of the human mind as born without innate ideas so that any knowledge is determined only by experience: "Let us then suppose the mind to be, as we say, white paper, void of all characters, without any ideas; how comes it to be furnished? Whence comes it by that vast store, which the busy and boundless fancy of man has painted on it with an almost endless variety? Whence has it all the materials of reason and knowledge? To this I answer, in one word, from EXPERIENCE; in that all our knowledge is founded, and from that it ultimately derives itself" [1]. Locke's conception of memory is that of a white paper, or a 'storehouse' of ideas, so that human memory is defined as an internal mental process aimed to store perceptions, impressions, and ideas. However, if memory is conceived as a 'container' of knowledge then by definition we assume that it can accumulate only to a limited volume. Clearly, such notion raises a problematic assumption, as it determines that some knowledge needs to be removed or forgotten in order for new knowledge to be preserved.

The study of human memory has progressed greatly beyond those early philosophical notions and currently involves clinical psychiatry, experimental psychology, neuropsychology, neurology, and a variety of other cognitive sciences. These have provided new insights into the human memory and managed to differentiate and isolate diverse structures and aspect of memory, such as immediate vs. long-term memory, procedural vs. declarative memory, retrieval vs. distortion of memory, and so forth $[2,3]$.

All these fields of research, whether psychological or neurological, share a common trait - they all provide legitimate notions that can be tested on living humans. Clearly, things get far more complicated when attempting to examine memory of extinct societies where we can easily recognize the difficulties of deducing cognitive processes and capabilities from lifeless material cultures.

When studying memory within the archaeological discipline, the concept of "Working Memory" is often used. This cognitive model, elaborated by experimental psychologists Baddeley and Hitch [4], was borrowed by archaeologists for the purpose of describing and understanding processes of knowledge procurement, maintenance, and enhancement. In the narrow sense, working memory is a system for the temporary holding and manipulation of information during the performance of a range of cognitive tasks (verbal or nonverbal) [5]. When the term working memory is used in the broadest sense, it refers to the new multicomponent cognitive model of Baddeley $[6,7]$, which involves several components, mainly the two subsystems of phonological loop and visuospatial sketch pad, and the supervisory controlling system of the central executive [8]. In addition, no complex human behavior is without some genetic influence, evolving through natural selection on genetic mutations over millions of years. Included within this broad spectrum of human behavior is the working memory, its executive functions, and its subsystems, which seem to have a strong genetic basis [8]. Archaeologists and paleoanthropologists are occupied with the question of whether working memory is indeed inherited or learned. It seems however that it is not an either-or system - executive functions appear to have a highly heritable component that is in addition reinforced by one's culture [8].

The use of the working memory model in archaeology has contributed mostly to studies of modern humans, suggesting that the development of working-memory was a driver of cognitive evolution and that its enhancement was a key component in the evolution of modern human behavior, particularly in the evolution of language $[9,10]$. However, it is far more difficult to project the concept of working memory on particular activities, tasks, or artifacts. Artifacts represent the major resource to track down behavioral developments in the archaeological record. By producing artifacts, or tools, humans do more than just make a given environment manageable; they generate cognitive elements of their specific environment [11]. Stone tools can be thus considered as

*Corresponding author: Nira Alperson-Afil, Martin (Szusz) Department of Land of Israel Studies and Archaeology, Institute of Archaeology, Bar-Ilan University, Ramat Gan, 52900, Israel

Accepted: March 28, 2019

Published online: March 30, 2019

Citation: Alperson-Afil N (2019) Demographic Changes as Triggers for the Loss of Skills during the Lower Palaeolithic Levant. Insights Anthropol 3(1):140-146 
significant indicators of past human cognition and as suitable representatives of past human memory. In this study, basalt bifacial tools are used as the representative artifacts of Lower Palaeolithic cultural processes, through which questions of appearance and disappearance of technological skills can be addressed.

This study attempts to explore possible interpretations for a loss of skills that occurred some half a million years ago. The particular skill under discussion is that of basalt tool-making, which was practiced for hundreds of thousands of years across a large geographic range. In the Levant, the earliest expertise of basalt knapping was applied mainly for the production of bifacial tools, and its appearance and disappearance occurred within the framework of the Lower Palaeolithic (1.6-0.25 Ma). The use of basalt for knapping was part of a larger set of capacities and experience of Lower Palaeolithic hominins. And yet, while the knowledge of biface production remained well structured in the memory of Lower Palaeolithic hominin groups, that of basalt exploitation and utilization seems to have been forgotten.

\section{Basalt Tool-Making}

The word "Basalt" is derived from Late Latin basaltes, which refers to "very hard stone". It is a grey - black volcanic rock, either fine- or coarse-grained, depending on the rate of cooling of lava on the surface. In comparison with other raw materials, basalt is considered by modern knappers as much more difficult to knap because it is less homogenous, making it harder to control the knapping [12].

In the Levant, basalt tools are one of the earliest artifacts found in prehistoric archaeological sites. Their first occurrence is recorded in Lower Palaeolithic sites where it is used mostly for the production of bifacial tools [13]. These tools, particularly handaxes and cleavers, are the typical morphotypes of the Acheulian Technocomplex [14-17].

Basalt tool making characterizes the early phases of the Acheulian in the Levant to such an extent so that bifacial tools are modified almost exclusively on basalt. Towards later phases of the Acheulian, basalt essentially disappears from the technological repertoire of the Levant and flint (a more homogenous, finer-grained, sedimentary rock, which is easier to knap) becomes the primary raw material used in tool making $[17,18]$.

After its disappearance, which lasted for some half a million years, the use of basalt returns primarily in the form of large grinding and pounding tools (e.g., bowls, mortars, and pestles). These tools, which characterize pre-agricultural and agricultural societies, served in completely different tasks and are considered as food processors for grain-based economies (Figure 1) [19].

\section{Basalt utilization in the Levatine Lower Palaeolithic}

The early introduction of knapping on volcanic coarsegrained raw materials in the Levant was part of the complete package of material culture that evolved in East Africa and entered the Levantine Corridor through the Out of Africa migration process. Throughout these long journeys, groups of early hominins preserved and brought into the Levant their environmental and cultural knowledge which is manifested in their tool kits. Two examples of the out of Africa process are recorded in the key sites of 'Ubeidiya and Gesher Benot Ya'aqov. There, basalt is used extensively for the production of quadrahedrals, trihedrals, and bifacial tools (alongside with few specimens on flint and limestone).

At the 1.6 Ma site of 'Ubeidiya [20] the majority of core tools (e.g., chopping tools) are made on flint, and their byproducts, flint flakes, constitute over $90 \%$ of the flakes and flake-tools assemblages. Thus, if the general frequencies of basalt artifacts are examined, regardless of tool type, in most of the 'Ubeidiya layers basalt artifacts amount to no more than $10 \%$ of the lithic assemblage (one exception is Layer K-30 where basalt artifacts constitute $43.8 \%$ of the assemblage, as $39.8 \%$ are basalt bifaces; Bar-Yosef and Goren-Inbar: page

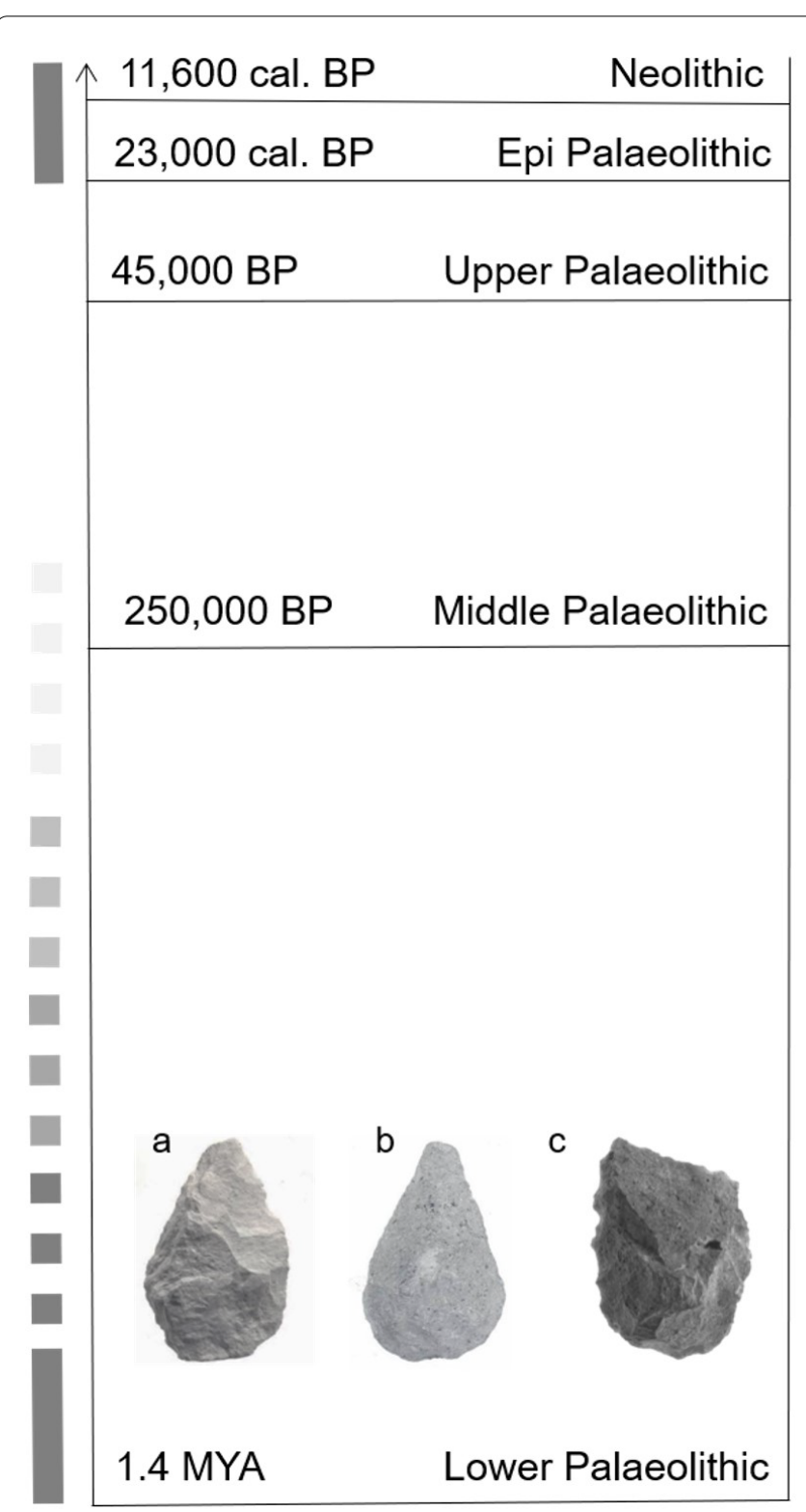

Figure 1: Schematic chronological framework for the appearance and disappearance of basalt tool-making in the Levant; a) Handaxe, 'Ubeidiya; b) Handaxe, Gesher Benot Ya‘aqov; c) Cleaver, Gesher Benot Ya‘aqov. 
125) [13]. However when bifacial tools are considered, “... basalt was clearly the preferred raw material for biface production, despite the occasional occurrence of specimens on flint and limestone" [13].

Similarly, at the 0.79 Ma site of Gesher Benot Ya'aqov a clear preference for basalt is evident when bifacial tools are examined, which remains consistent all along the occupational sequence. Handaxes were dominantly made on basalt, and with few exceptions (on limestone) cleavers were exclusively made on basalt. Thus, basalt bifaces constitute $95.2 \%$ ( $N$ $=521$ ) of the entire biface assemblage [21]. The use of flint and limestone for tool production is more prominent in other tool categories (e.g., chopping tools and retouched flaketools). The few flint handaxes found at Gesher Benot Ya'aqov demonstrate a high degree of craftsmanship so it is not a lack of production knowledge that limited their manufacture.

While in Africa hominins continue to modify their bifacial tools on coarse-grained materials [17], in the Levant the use of the coarse-grained basalt stopped almost drastically and bifacial tools - similar in technology and morphology - were instead modified on finer-grained flint.

This phenomenon is clearly illustrated in sites where


Figure 2: a) Geological map of Israel; basalt and tuff are marked red and purple; b) Distribution map of Lower Palaeolithic sites and their associated lithology: Basalt and tuff (red), chalk chert and limestone (yellow), other (black). 
despite the high availability of basalt, hominins seem to have preferred the use of flint for the production of their bifacial tools.

The distribution map of Lower Palaeolithic sites (Figure 2 ), integrated into the different lithologies available for their use in knapping, illustrates that procurement of basalt was feasible in a large number of sites (marked red on the map). It would be reasonable to expect that in these northern sites, where basalt is widely available, extensive use of basalt will be present. And yet, Acheulian bifacial tools are present in all those sites however, with the exception of the early sites of 'Ubeidiya and Gesher Benot Ya'aqov, in all other, later, sites, bifacial tools are modified primarily on flint.

The site of Berekhat Ram, for example, is located on the foot of Mount Hermon, in the Golan Heights. Despite the high availability of good quality basalt in the area, the entire stone tools assemblage is modified on flint and only a single basalt biface was found [22]. The site is well known for the small red tufic pebble (volcanic ash) with several deep grooves which is considered to represent the earliest example of an anthropomorphic figure [23-25].

Another example is the site of Ma'ayan Barukh, deposited on basalt beds on the northern slopes of the Hula Plain. It has not been excavated and all the reported data relates to surface collections. Despite the fact that basalt is found extensively in the vicinity of the site, very few basalt artifacts were found (only 2 flakes, and 3 hammer stones were reported), while the remaining thousands bifaces and other stone tools are all made on flint [26]. At Joubbata, located in a volcanic terrain at the Golan Heights, the presence of handaxes have ascribed this surface collection to the Acheulian Technocomplex [27]. Again, Despite the fact that basalt is found extensively in the vicinity of the site, the entire assemblage $(N=513)$ is modified on flint [27]. Similar examples can be found in the Lower Palaeolithic sites of Ramat Yiron [28] where despite the high availability of basalt, biface production is restricted to flint.

Thus, the long Acheulian Technocomplex in the Levant initiates with sites in which a clear preference for the use of basalt for biface production is recorded. It continues, and comes to an end, with sites in which despite its availability basalt is virtually missing from the lithic assemblages.

\section{Basalt Forgetting}

What may be the possible explanations for the disappearance of basalt tool-making? Potential reasons may perhaps relate to the inexplicable symbolic realm of these cultures, to the availability of raw material, to variations in functionality, or to forgetting of technological skills. In studies of modern societies, forgetting is often associated with different adaptive strategies (e.g., following trauma: $[29,30]$. When volcanic materials are concerned, clearly we should bear in mind the volcanic activity involved in their formation. Specifically, the Pleistocene humans under discussion lived in a world of recurrent volcanic activity, and likely witnessed volcanic eruptions. We can only wonder about the impact of such volcanic events on those ancient populations and on their choices of raw material. Thus, we should not ignore the fact that of all available lithic resources, the volcanic ones were the only raw materials which their actual formation was observed. This unique situation may have led humans to attribute symbolic qualities to these raw materials (possibly as in the tufic anthropomorphic figurine of Berekhat Ram, mentioned above), as suggested for basalt use in later periods [19].

As for raw material availability, the occurrence of sites in the Northern Hula plain and the Golan Heights, where basalt is excessively available and yet flint is the raw material in use, suggests that the availability of raw material cannot serve as a reasonable explanation. Early humans had clear preferences with regards to raw material. In earlier phases of the Acheulian, the preference for coarser-grained rocks is clear even in cases where fine-grained rocks are available and is characteristic of both the African Acheulian and the Levantine one [17]. In later phases of the Acheulian in the Levant, the raw material preferences shifted toward exploitation of finergrained material (flint) despite the availability of volcanic rocks.

If functional causes are considered, then it has to be assumed that working with basalt tools became less efficient for the required tasks such as butchering, cutting, digging, etc. However, according to the available archaeological record, the fossil bone assemblages throughout the Lower Palaeolithic do not change significantly and the same types of animals persist throughout a long period of time. Thus, there are no indications for a change in the dietary requirements. In addition, the most striking notion about the shift in raw material is the fact that the tools themselves hardly change. In fact, the same types of tools - bifaces - with the same morphology continued to be in use with the only difference being the change in raw material (morphologically, cleavers are an exception and are discussed in more detail below). These suggest that the same tasks, which required the same tool types, were still carried out.

We thus remain with the last explanation for the disappearance of basalt tool production: forgetting. Interestingly, despite the antiquity of this process, we can isolate nearly exactly what was forgotten - not the knowledge of knapping and not the knowledge of biface production and modification but specifically the knowledge of working with basalt. Having isolated the particular forgotten knowledge, it is called upon to explore the possible mechanisms involved in the process of that forgetting.

Such mechanisms are described in the work of Rivers [31] who studied several groups of hunters-gatherers living on different islands of the Pacific Ocean. He specifically explored the disappearance of three basic components of their material culture: pottery, the canoe, and the use of bow and arrow. All these elements can be considered essential for the daily life of these groups, which engaged in sea faring between islands, hunting or warfare using bow and arrow, and a variety of daily food preparation activities involving pottery. And yet, surprisingly, Rivers discovered that amongst different groups, the knowledge of making and using these basic elements was once practiced but forgotten. Rivers proposed a sociological explanation for this loss of skills. He noted that technical 
knowledge was often the preserve of specialists, and if for any reason the specialist group declined in numbers, so would the transmission of the skills be endangered. According to Rivers then, a hole in the population would make a hole in the collective memory [31]. Rivers' explanation basically assumes that cultural knowledge is by definition not in the possession of individuals but rather it is a social, collective asset. This view of collective forgetting is very close to that of the French sociologist Maurice Halbwachs [32] which provided an extensive analysis of how social groups remember their collective pasts, suggesting that all memories are in some sense collective rather than individual. In his view, it is not the individual mind that primarily organizes memory but shared cognitive structures, or 'frames' of memory, that exist in any social groupings. Halbwachs held that the organization of remembering is a fundamental concern of every human society, and because human individuals are always social beings, they remember and forget according to the memory frames and practices of the groups of which they are members. Following this line of thought, the concept of a 'social memory' is also embraced by recent memory studies $[33,34]$. Schudson [35] for example assumes that"... there is no such thing as individual memory... Memory is social... it is located in institutions rather than in individual human minds in the form of rules, laws, standardized procedures, and records, a whole set of cultural practices through which people recognize a debt to the past" (p. 346).

\section{Discussion}

Let us return to Rivers' study and to our main concern - the disappearance of skills, and in particular those of basalt tool making in the Lower Palaeolithic Levant. Rivers specifically pointed out that it is the movement of people that enhanced the disappearance of knowledge. Similarly, a loss of cultural knowledge which was triggered by demographic changes is recorded in the Tasmanian study of Henrich [36], where the loss of particular kinds of skills and technologies was caused by relatively sudden reduction in the population. The notion of demographic changes as triggers for the loss of cultural knowledge is particularly important when discussing prehistoric cultures, for which movements and migrations are recurrently documented. The specific time period which we are concerned with, the Lower Palaeolithic, is a period of continuous movements.

In attempts to reconstruct human dispersals based on the distribution of bifacial tools, and specifically basalt ones, these tools are in fact used as 'road signs'. According to Bar-Yosef and Belfer-Cohen (2013) [37], "...the justification for using stone tools as 'road signs' is based on the recognition that given the availability of suitable raw materials the technomorphological attributes of stone tools are determined by the particular knapping traditions, thought, learned, and practiced within each social entity..." (p. 32).

Efforts to reconstruct early human dispersals, and in particular those of the Acheulian Technocomplex, are widely attempted and it is far beyond the scope of this study to recreate comprehensive world-wide dispersal routes. It is however suggested that the disappearance of knapping of coarse-grained materials, such as basalt, during this period should be viewed as a "...sudden change in the 'road signs'... evidence to identify movements of groups across vast landscapes, adhering to their own particular technical tradition" [37]. Such movements, as suggested by Rivers [31], could have led to the loss of cultural knowledge and eventually to the disappearance of knapping of coarsegrained materials.

The change in cultural knowledge throughout the Acheulian is characterized not only by the disappearance of coarse-grained materials from the lithic repertoire. It involved in addition typological and technological alterations. Typologically, cleavers are an example of a fundamental difference between the early and middle Acheulian and the later phases of the Acheulian [18]. These bifacial tools are modified virtually exclusively on coarse-grained materials and are nearly absent from late Levantine Acheulian assemblages $[17,18]$. Technologically, the bifacial tools of the early and middle Acheulian are modified more often on large flakes, requiring only minimal additional design [17]. This technique also disappears and late Acheulian bifaces are instead modified on pebbles/nodules.

The general scheme of the Levantine Acheulian illustrates that the first hominins to enter the area brought with them the complete package of African knowledge which involved the ability to knap and modify volcanic coarse-grained materials into large flakes from which they produced bifacial tools, handaxes as well as cleavers. This cultural package has altered in the course of the Lower Palaeolithic, and a different Acheulian package appeared where fine-grained materials are preferred, cleavers are absent, and handaxes are modified mostly on pebbles/nodules. It thus seems reasonable to propose that groups of new collective knowledge inhabited the Levant.

Several suggestions may be considered regarding the origin of these populations. The first assumes that, similarly to other Lower Palaeolithic lithic traditions, this new Acheulian population originates in Africa, and represents another migration wave in the out-of-Africa process. The older Acheulian preferences, of coarse-grained materials for the production of bifacial tools on flakes (including cleavers), persisted in Sub-Saharan Africa until the very last stages of the Acheulian. At the same time, during later stages of the Acheulian, other African sites display a trend towards finergrained materials, fewer cleavers, and more extensively flaked handaxes. It is possible that such Acheulian groups colonized the Levant, introducing their new preferences for finer-grained materials and their different flaking methods for the production of handaxes. The other possibility suggests an opposite direction. Human migration out of Africa did not stop at the Levant, and continued into the southern parts of Europe. There, coarse-grained materials are not easily available (Figure 3) and bifacial tools are modified nearly exclusively on finer-grained materials such as flint/chert. Is it possible that European groups made their way back into the Levant, practicing their familiar modes of preparing bifacial tools - on finer-grained materials only, and leaving behind Levantine sites where no basalt use is recorded, despite its 


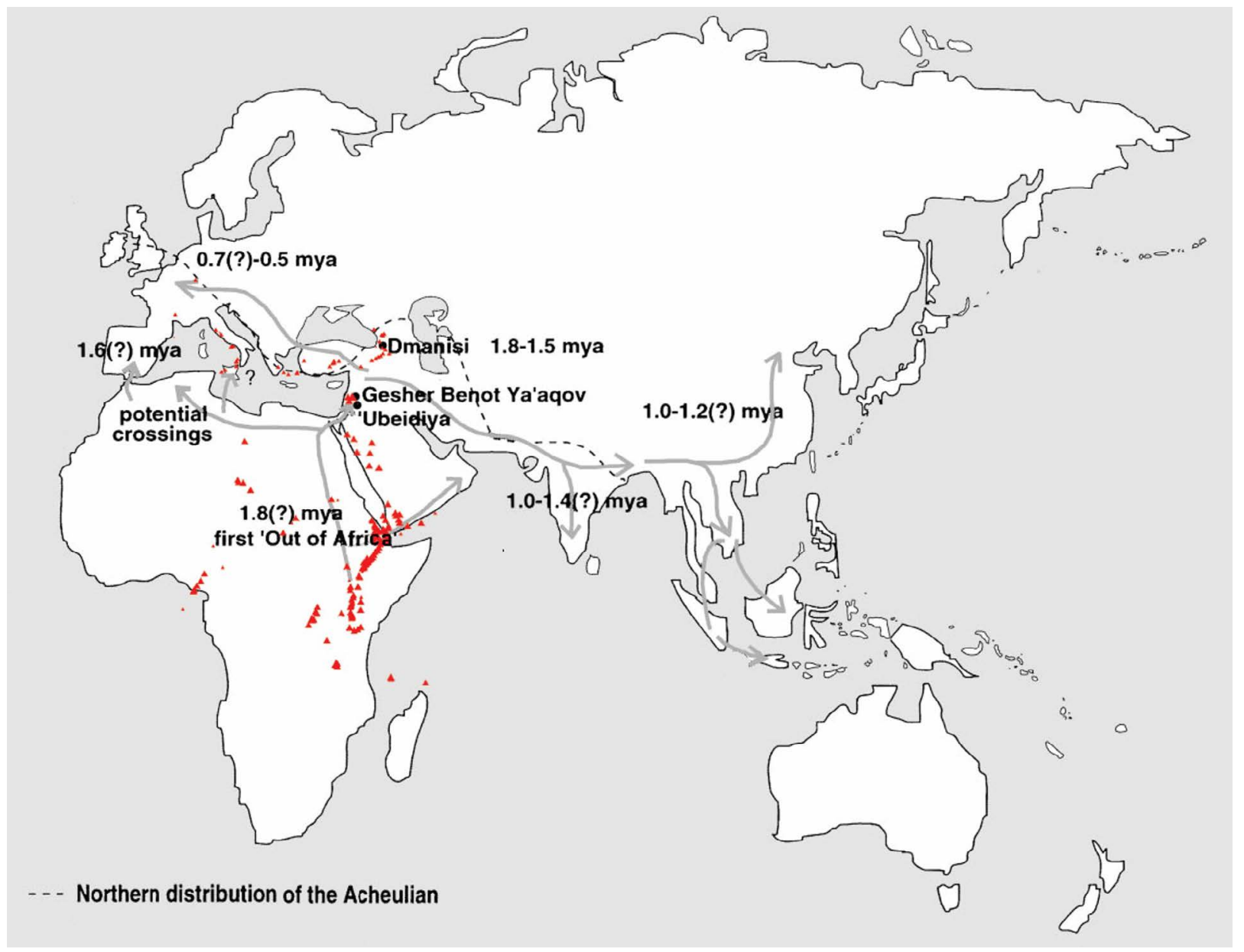

Figure 3: Suggested routes for early colonizations from Africa [39] embedded with volcanoes (red triangles) of Africa, Red Sea, Mediterranean and Western Asia [40].

availability? Animal fossil bones found at prehistoric sites, suggest that the Levantine Corridor served as a primary dispersal route for Plio-Pleistocene animals. Thus, the idea that European prehistoric cultures penetrated the Levant during the Lower Palaeolithic may be supported by the fact that mammals of Eurasian origin penetrated into Africa during that period. Examples can be found in the elephant Mammuthus meridionalis, originally of African origin, which colonized Eurasia during the Late Pliocene and returned to North Africa during the Early Pleistocene; and in the carnivore Canis (Xenocyon) ex. gr. falconeri (synonym of Lycaonlycaonoides) ancestor of the wild dog, which is known from North, South, and East Africa (including Olduvai beds I and II) [38]. These animal movements point to the fact that migration routes were available for the North-to-South direction, so that human groups of European origin could similarly arrive into the Levant.

To sum, when analyzing ancient prehistoric cultures we often cannot obtain high-resolution conclusions on the specifics of different cultural process. When addressing the loss of technological skills, we can however relate to stone tools as representatives of human memory, as well as 'road signs' for population dispersals. Thus, it is suggested that the relatively drastic shift from the coarser-grained basalt to the finer-grained flint for the production of bifacial tools, which is recorded in the Lower Palaeolithic of the Levant, reflects the loss of collective skills resulting from population movements that carried cultural knowledge across space and time, a process which unavoidably led to forgetting.

\section{References}

1. Locke J (1689) An essay concerning human understanding. Clarendon Press, Oxford.

2. Schacter DL (1995) Memory distortion: History and current status. In: DL Schacter, Memory distortion: How minds, brains, and societies reconstruct the past. Harvard University Press, Cambridge, England, 1-43.

3. Squire LR, JT Wixted (2011) The cognitive neuroscience of human memory since HM. Annu Rev Neurosci 34: 259-288.

4. Baddeley A, GJ Hitch (1974) "Working memory," in recent advances in learning and motivation. In: GA Bower, Academic Press, New York, 47-90.

5. Baddeley A (1986) Working Memory. Oxford Psychology Series 11. Clarendon Press, Oxford, 289.

6. Baddeley A (2001) Is working memory working?. American Psychologist 56: 851-864.

7. Baddeley A (2012) Working memory: Theories, models, and controversies. Annual Review of Psychology 63: 1-29. 
8. Wynn T, FL Coolidge (2010) Beyond symbolism and language: An introduction to supplement 1, working memory. Current Anthropology 51: S5-S16.

9. Baddeley A (2003) Working memory and language: An overview. J Commun Disord 36: 189-208.

10. Reuland E (2010) Imagination, planning, and working memory: The emergence of language. Current Anthropology 51: S99-S110.

11. Haidle MN (2010) Working-memory capacity and the evolution of modern cognitive potential: Implications from animal and early human tool use. Current Anthropology 51: S14-S166.

12. Madsen B, N Goren-Inbar (2004) Acheulian giant core technology and beyond: An archaeological and experimental case study. Eurasian Prehistory 2: 3-52.

13. Bar-Yosef O, N Goren-Inbar (1993) The Lithic Assemblages of 'Ubeidiya: A lower palaeolithic site in the jordan valley. Qedem 34, The Institute of Archaeology Hebrew University, Jerusalem.

14. Clark JD (1994) "The Acheulian industrial complex in Africa and elsewhere," in integrative paths to the past-paleoanthropological advances in honor of F. Clark Howell. In: RS Corruccini, RL Ciochon, Prentice Hall, Englewood Cliffs, USA, 451-469.

15. Isaac GL (1977) Olorgesailie: Archeological Studies of a Middle Pleistocene Lake Basin in Kenya. The University of Chicago Press, Chicago, Illinois.

16. Kleindienst MR (1962) Components of the East African Acheulian assemblages: An analytic approach. In: Mortelmans G, Actes du IVemeCongres Panafricain de Prehistoire et de I'Etude du Quaternaire, 81-105.

17. Sharon $G$ (2007) Acheulian large flake industries: Technology, chronology, and significance. Vol. 1701. BAR (British Archaeological Reports) International Series, Archaeopress, Oxford.

18. Gilead D (1970) Early palaeolithic cultures in israel and the near east. Unpublished Ph.D. dissertation, Hebrew University of Jerusalem.

19. Ronen A (2010) "The symbolic use of basalt in the Levantine Epipalaeolithic and the emergence of socioeconomic leadership," in The principle of sharing. Segregation and construction of social identities at the transition from foraging to farming, studies in early near eastern production, subsistence, and environment 14 . In: Edited M Benz, ex oriente, Berlin, Germany, 213-222.

20. Martinez-Navarro B, Belmaker M, O Bar-Yosef (2009) The large carnivores from 'Ubeidiya (early Pleistocene, Israel): Biochronological and biogeographical implications. J Hum Evol 56: 514-524.

21. Sharon G, Alperson-Afil N, N Goren-Inbar (2011) Cultural conservatism and variability in the acheulian sequence of Gesher Benot Ya'aqov. J Hum Evol 60: 387-397.

22. Goren-Inbar N (1985) The lithic assemblage of the berekhat ram acheulian site, Golan Heights. Paleorient 11: 7-28.
23. d'Errico F, A Nowell (2000) A new look at the Berekhat Ram figurine: Implications for the origins of symbolism. Cambridge Archaeological Journal 10: 123-167.

24. Goren-Inbar (1986) A figurine from the acheulian site of berekhat ram. Mitekufat Haeven 19: 7-12.

25. Goren-Inbar N, S Peltz (1995) Additional remarks on the Berekhat Ram figurine. Rock Art Journal 12: 131-132.

26. Stekelis M, D Gilead (1966) Maayan barukh - A lower palaeolithic site in upper galilee. Mitekufat Haeven, Jerusalem, Israel,8.

27. Goren N (1979) An Upper Acheulian industry from the Golan Heights. Quartar 29/30: 105-121.

28. Ohel MY (1980) A note on Acheulean sites at Ramat Yiron, Israel: Some preliminary results. Quaternaria 22: 121-129.

29. Connerton P (2008) Seven types of forgetting. Memory Studies 1: $59-71$.

30. Erdelyi MH (2008) Forgetting and remembering in psychology: Commentary on Paul Connerton's 'Seven types of forgetting' (2008). Memory Studies 1: 273-278.

31. Rivers WHR (1912) The Disappearance of Useful Arts. In: J Simelii Arvingars Boktrycheviaktiebolag, Westermarck, Helsinki, Finland.

32. Halbwachs M (1925) Les Cadres Sociaux de la Memoire. Les Presses Universitaires de France, Paris.

33. Brockmeier J (2002) Remembering and forgetting: Narrative as cultural memory. Culture Psychology 8: 15-43.

34. Johnson M (1991) The imaginative basis of meaning and cognition. In: Melion W, Kuchler S, Images of memory. Smithsonian Institution Press, Washington, 74-87.

35. Schudson M (1995) "Dynamics of distortion in collective memory," in Memory Distortion: How Minds, Brains, and Societies Reconstruct the Past. In: DL Schacter, Harvard University Press, Cambridge, 346-364.

36. Henrich J (2004) Demography and cultural evolution: How adaptive cultural processes can produce maladaptive losses: The Tasmanian case. American Antiquity 69: 197-214.

37. Bar-Yosef O, A Belfer-Cohen (2013) Following Pleistocene road signs of human dispersals across Eurasia. Quaternary International 285: 30-43.

38. Martinez-Navarro B (2004) "Hippos, pigs, bovids, saber-toothed tigers, monkeys, and hominids: Dispersals through the Levantine Corridor during late Pliocene and early Pleistocene times," in Human Paleoecology in the Levantine Corridor. In: N GorenInbar, JD Speth, Oxbow Books, Oxford, 37-51.

39. Bar-Yosef O, A Belfer-Cohen (2001) From africa to eurasia: Early dispersals. Quaternary International 75: 19-28.

40. Siebert L, T Simkin (2002) Volcanoes of the World: An illustrated catalog of holocene volcanoes and their eruptions. Smithsonian Institution, Global Volcanism Program Digital Information Series, GVP-3.

DOI: $10.36959 / 763 / 497$

Copyright: (C) 2019 Alperson-Afil N. This is an open-access article distributed under the terms of the Creative Commons Attribution License, which permits unrestricted use, distribution, and reproduction in any medium, provided the original author and source are credited. 